\title{
Is there a Relationship between Blood Lipid Profile and Lumbar Spinal Stenosis?
}

\author{
Ezgi Akar, (i) Mustafa Efendioğlu
}

Department of Neurosurgery, University of Health Sciences Hamidiye Faculty of Medicine, Haydarpasa Numune Health Application and Research Center, Istanbul, Turkey

\begin{abstract}
Introduction: The etiology of lumbar spinal stenosis (LSS) is still unknown, but it is a multifactorial disease. Reduced blood flow due to atherosclerosis is thought to accelerate spinal degenerative changes, but it is not known whether there is a relationship between blood lipid profile and the development of spinal stenosis. In this study, we compared the LSS patients who underwent surgery and the patients without narrow canal findings., We aimed to evaluate the role of hyperlipidemia in the etiology of spinal stenosis.

Methods: In our study, the blood lipid values (total cholesterol, triglyceride, LDL cholesterol, HDL cholesterol) of two different groups between the ages of 60 and 70, consisting of women and men, were analyzed and compared retrospectively. Group 1 (LSS group) with 40 LSS cases (20 females/20 males) operated in our clinic, Group 2 (control group)with the patients from patients who applied to the outpatient clinic for nonspecific reasons (such as headache).

Results: There was no statistically significant difference in Group 1 and Group 2 concerning HDL and LDL levels. The VLDL level of Group 1 was statistically significantly higher than Group 2 ( $p=0.000 ; p<0.05)$. The triglyceride level of Group 1 was statistically significantly higher than Group 2 ( $p=0.000 ; p<0.05)$.

Discussion and Conclusion: It is thought that there is a relationship between VLDL and triglyceride levels and the development of spinal stenosis. However, there is no such relationship with HDL and LDL.

Keywords: Atherosclerosis; degenerative changes; dyslipidemia; lumbar spinal stenosis.
\end{abstract}

W ith the human gaining an upright posture, low back pain has become a discomfort that has been experienced at least once in a lifetime and may develop for many reasons, adversely affecting daily life. In routine practice, the most common cause of low back pain is lumbar spinal stenosis (LSS) and is the main indication of spinal surgery, especially in cases over 50 years of age ${ }^{[1]}$. The most specific symptom of LSS is neurogenic claudication (pain, numbness and feeling of pain in the legs that are exacerbated by walking and standing for a long time). There is often no correlation between the amount of spinal narrowing in radiological images and the degree of symptoms we encounter in the clinic ${ }^{[2,3]}$. In other words, not only mechanical compression but also decreased blood flow to nerve roots play a role in the pathology of LSS[4].

Blood flow to the lumbar vertebra, intervertebral discs, nerve roots, and paravertebral muscles are supplied by the iliac arteries and branches originating from the abdominal

Correspondence (İletişim): Ezgi Akar, M.D. Saglik Bilimleri Universitesi Hamidiye Tip Fakultesi, Haydarpasa Numune Saglik Uygulama ve Arastirma Merkezi, Norosirurji Anabilim Dali, Istabul, Turkey

Phone (Telefon): +90 2163868263 E-mail (E-posta): ezgiaycicek@gmail.com

Submitted Date (Başvuru Tarihi): 18.02.2020 Accepted Date (Kabul Tarihi): 20.02.2020

Copyright 2020 Haydarpaşa Numune Medical Journal

OPEN ACCESS This is an open access article under the CC BY-NC license (http://creativecommons.org/licenses/by-nc/4.0/). 
aorta $^{[5]}$. An atherosclerotic plaque in the abdominal aorta reduces blood flow to the lumbar arteries, which accelerates degenerative changes in the spine ${ }^{[6]}$. Hypertension, diabetes mellitus, and hyperlipidemia are the main cardiovascular risk factors, triggering the development of atherosclerosis and thus causing a decrease in peripheral blood flow ${ }^{[6,7]}$. In many studies, a relationship between intervertebral disc degeneration and blood lipid profile has been demonstrated ${ }^{[8,9]}$. The underlying mechanism here is; atherosclerosis due to hyperlipidemia and ischemia that arise from the decreased blood flow in the intervertebral disc and surrounding tissues ${ }^{[9]}$. LSS is a disease that emerges with advancing age, and the defect in the blood lipid profile is more common with advancing age. Therefore, the role of hyperlipidemia and blood lipid profile disorder in the etiopathogenesis of LSS is uncertain. In our study, by comparing the blood lipid profiles of two groups of similar ages, we aimed to investigate whether there is a relationship between the deterioration in major lipid parameters and the development of LSS.

\section{Materials and Methods}

Blood lipid profile values (triglyceride, LDL, HDL, VLDL) of 40 patients ( 20 females $/ 20$ males) who applied to our clinic between 2017-2019 and had established a diagnosis of LSS and operated in consideration of neurological and radiological examinations were analyzed retrospectively (Group 1). In the control group (Group 2), blood lipid values of 40 patients (20 females/20 males) without low back and leg pain and spinal stenosis at any level who had been admitted to the outpatient clinic for any nonspecific reason at the same time interval were examined. To create a homogeneous study group, patients aged between $60-70$ years were selected, and an equal number of male and female patients were included in this study. All patients had no other serious neurological symptoms, serious cardiovascular disease and organ failure (heart, kidney, liver, or respiratory), psychiatric symptoms, and peripheral artery disease. All selected cases had a body mass index of $<30 \mathrm{~kg} / \mathrm{m}^{2}$, and cases with obesity were excluded from this study. According to the examination made from the archive records of the patients, smokers were not included in this study. Triglyceride, LDL, HDL, VLDL values of both groups were compared statistically.

\section{Statistical Analysis}

When evaluating the findings obtained in this study, IBM SPSS Statistics 22 for statistical analysis (SPSS IBM, Turkey) programs were used. The suitability of the parameters to normal distribution was evaluated with the Shapiro-Wilks test. Student's t-test was used for comparisons of normally distributed parameters between two groups, and the Man$\mathrm{n}$-Whitney $\mathrm{U}$ test was employed for comparisons of nonnormally distributed parameters between two groups. Significance was evaluated at the level of $p<0.05$.

\section{Results}

There was no statistically significant difference between both groups concerning HDL and LDL levels $(p>0.05)$. The VLDL level of Group 1 was statistically significantly higher than Group $2(p=0.000 ; p<0.05)$. The triglyceride level of Group 1 was statistically significantly higher than Group 2 $(p=0.000 ; p<0.05)$ (Table 1).

\section{Discussion}

The pathophysiological mechanism and underlying causes of lumbar spinal stenosis and spinal degenerative diseases are still not fully understood. Many environmental and hereditary factors, such as abnormal mechanical loading, MMPs and ADAMTS gene upregulation, aging, smoking, hormonal factors and hereditary features, are thought to contribute to the development of $\mathrm{LSS}^{[10]}$. Since most of the LSS cases are at an advanced age ( $>60$ years old), chronic diseases (such as hypertension, diabetes mellitus, dyslipidemia, osteoporosis and cerebrovacular diseases) are frequently encountered and expected ${ }^{[11]}$. The frequency of comorbid diseases increases at advanced ages, but their roles in LSS etiology are uncertain. Arterial calcification and atherosclerosis diseases, such as hypertension, dyslipidemia, diabetes mellitus, are considered as risk factors not only for coronary artery diseases but also for spinal degenerative diseases, and their roles in the etiology of low back pain and intervertebral disc herniation have been the subject of many studies in the past years ${ }^{[12-14]}$.

According to the 'Framingham Study,' which was performed over 25 years and examined the effects of atherosclerosis on lumbar vertebral diseases, lumbar vertebral

Table 1. Intergroup assessments of the study parameters

\begin{tabular}{lccc}
\hline \multirow{2}{*}{ Spinal Stenosis } & \multicolumn{2}{c}{ Control } & \multirow{2}{*}{ p } \\
\cline { 2 - 3 } & Mean \pm SD & Mean \pm SD & \\
\hline $\mathrm{HDL}$ & $46.78 \pm 12.11$ & $51 \pm 13.21$ & ${ }^{1} 0.140$ \\
$\mathrm{LDL}$ & $133.38 \pm 38.97$ & $122.33 \pm 27.45$ & ${ }^{1} 0.147$ \\
$\mathrm{VLDL}$ & $34.81 \pm 22.96(29)$ & $22.63 \pm 12.91(20)$ & ${ }^{2} 0.000^{*}$ \\
$\mathrm{TG}_{\text {(medyan) }}$ & $221.15 \pm 50.07(208)$ & $106.35 \pm 57.12(88.5)$ & ${ }^{2} 0.000^{*}$ \\
\hline
\end{tabular}

${ }^{1}$ Student t-test; ${ }^{2}$ Mann-Whitney U Test; ${ }^{*} \mathrm{p}<0.05$. 
degenerative diseases, and low back pain was observed to be increased in patients with abdominal aortic calcification $^{[15]}$. Backache arises from degeneration of the intervertebral disc and other peripheral structures. In studies conducted, it has been shown that degeneration develops in the intervertebral disc and causes low back pain and lumbar disc herniation with reduced blood flow from the lumbar segmental arteries to the intervertebral disc and surrounding spinal structures ${ }^{[10,15,16]}$. Since atherosclerosis occurring in the abdominal aorta will decrease blood flow in the lumbar segmental artery, the factors causing atherosclerosis and their relationship with lumbar degenerative diseases have attracted the attention of spinal surgeons. In a cadaver study of $\mathbf{8 6}$ male cases, atherosclerosis and plaque formation were observed in the ostium of the lumbar segmental arteries, and especially in the lumbar segmental arteries, which were thought to be associated with lumbar disc degeneration ${ }^{[17]}$. In our study, we aimed to investigate whether there is a relationship between LSS cases and abnormal blood lipid levels.

In some studies, there was a relationship between cholesterol levels and other cardiovascular risk factors and hip, knee and other joint osteoarthritis, rotator cuff rupture and Achilles tendon rupture ${ }^{[16]}$. The relationship between low back pain and sciatalgia and abnormal LDL and triglyceride levels has been evaluated in many studies and it has been reported that there is a correlation, especially between $L D L$ levels and the severity of symptoms ${ }^{[17]}$. In a study by Longo et al. ${ }^{[9]}$, a moderate increase in triglyceride $(162 \mathrm{mg} / \mathrm{dl})$ and total cholesterol $(215 \mathrm{mg} / \mathrm{dl})$ levels was found in patients with lumbar disc herniation aged 59 years and older. However, in this study, patients are older, and gender distribution is uneven, which reduces the reliability of this study. Menopause and estrogen are hormonal factors that affect blood lipid profile ${ }^{[13,15]}$. To eliminate the effects of gender on blood lipid profiles, two homogeneous groups of men and women were included in our study. Also, since the high obesity and body mass index may also be a risk factor for spinal degenerative diseases, the body mass index of the patients we included in our study was selected as $<30 \mathrm{~kg} /$ $\mathrm{m}^{2}$. These factors make our work different and privileged from previous studies. When estimating risk in atherosclerotic diseases, it is recommended to evaluate not only total cholesterol and triglyceride levels but also the main risk factors, i.e., LDL and HDL cholesterol levels ${ }^{[18]}$. In most of the studies on spinal degeneration, only total cholesterol and triglyceride levels were measured. In our study, besides triglycerides, LDL and HDL were examined, which constitutes another distinguishing feature of our study. In our study, in cases with spinal stenosis, VLDL and triglyceride levels were observed to be higher than normal. However, HDL and LDL levels were similar in control subjects and patients with stenosis.

In our study, there are limitations like many previous studies. Firstly, the incidence of LSS increases with age, and the probability of dyslipidemia also increases at older ages. This raises the question of whether the defect in the blood lipid profile is an etiological factor or a concomitant condition. The other is that LSS is a multifactorial disease that can be seen congenitally and it can be thought that dyslipidemia can only contribute to acquire LSS. These findings can be supported by studies with a more number of cases.

\section{Conclusion}

Based on the data we obtained in our study, we think that VLDL and triglyceride levels may be associated with the development of lumbar spinal stenosis. However, there is no relationship between LDL and HDL levels and development of lumbar spinal stenosis. By keeping the serum lipid profile within normal limits, a new approach can be provided in the development, prevention and treatment of spinal degenerative diseases.

Ethics Committee Approval: Haydarpaşa Numune Training and Research Hospital Chief Physician approved. Date: 04.02.2020 No: 62977267-000-1781.

Peer-review: Externally peer-reviewed.

Authorship Contributions: Concept: E.A.; Design: E.A.; Data Collection or Processing: M.E.; Analysis or Interpretation: E.A.; Literature Search: E.A.; Writing: E.A.

Conflict of Interest: None declared.

Financial Disclosure: The authors declared that this study received no financial support.

\section{References}

1. Watters WC 3rd, Baisden J, Gilbert TJ, Kreiner S, Resnick DK, Bono CM, et al; North American Spine Society. Degenerative lumbar spinal stenosis: an evidence-based clinical guideline for the diagnosis and treatment of degenerative lumbar spinal stenosis. Spine J 2008;8:305-10. [CrossRef]

2. Sirvanci M, Bhatia M, Ganiyusufoglu KA, Duran C, Tezer M, Ozturk $C$, et al. Degenerative lumbar spinal stenosis: correlation with Oswestry Disability Index and MR imaging. Eur Spine . 2008;17:679-85. [CrossRef]

3. Sekiguchi M, Aoki Y, Konno S, Kikuchi S. The effects of cilostazol on nerve conduction velocity and blood flow: acute and chronic cauda equina compression in a canine model. Spine (Phila Pa 1976) 2008;33:2605-11. [CrossRef]

4. Haig AJ, Geisser ME, Tong HC, Yamakawa KS, Quint DJ, Hoff 
JT, et al. Electromyographic and magnetic resonance imaging to predict lumbar stenosis, low-back pain, and no back symptoms. J Bone Joint Surg Am 2007;89:358-66. [CrossRef]

5. Crock HV, Yoshizawa $H$. The blood supply of the lumbar vertebral column. Clin Orthop Relat Res 1976;(115):6-21. [CrossRef]

6. Kauppila LI, McAlindon T, Evans S, Wilson PW, Kiel D, Felson DT. Disc degeneration/back pain and calcification of the abdominal aorta. A 25-year follow-up study in Framingham. Spine (Phila Pa 1976) 1997;22:1642-7. [CrossRef]

7. Cernes R, Zimlichman R, Shargorodsky M. Arterial elasticity in cardiovascular disease: focus on hypertension, metabolic syndrome and diabetes. Adv Cardiol 2008;45:65-81. [CrossRef]

8. Leino-Arjas P, Kauppila L, Kaila-Kangas L, Shiri R, Heistaro S, Heliövaara M. Serum lipids in relation to sciatica among Finns. Atherosclerosis 2008;197:43-9. [CrossRef]

9. Longo UG, Denaro L, Spiezia F, Forriol F, Maffulli N, Denaro V. Symptomatic disc herniation and serum lipid levels. Eur Spine J 2011;20:1658-62. [CrossRef]

10. Zhang Y, Zhao Y, Wang M, Si M, Li J, Hou Y, et al. Serum lipid levels are positively correlated with lumbar disc herniation--a retrospective study of 790 Chinese patients. Lipids Health Dis 2016;15:80. [CrossRef]

11. Stairmand JW, Holm S, Urban JP. Factors influencing oxygen concentration gradients in the intervertebral disc. A theoretical analysis. Spine (Phila Pa 1976) 1991;16:444-9. [CrossRef]

12. Kauppila LI, Mikkonen R, Mankinen P, Pelto-Vasenius K, Mäenpää I. MR aortography and serum cholesterol levels in patients with long-term nonspecific lower back pain. Spine (Phila $\mathrm{Pa}$
1976) 2004;29:2147-52. [CrossRef]

13. Keser N, Celikoglu E, İs M, İlgezdi ZD, Sunar B, Aydin YS, et al. Is there a relationship between blood lipids and lumbar disc herniation in young Turkish adults? Arch Med Sci Atheroscler Dis 2017;2:e24-e28. [CrossRef]

14. Kurunlahti M, Tervonen O, Vanharanta H, Ilkko E, Suramo I. Association of atherosclerosis with low back pain and the degree of disc degeneration. Spine (Phila Pa 1976) 1999;24:2080-4.

15. Nakamura Y, Yamamoto T, Okamura T, Kadowaki T, Hayakawa T, Kita Y, et al; NIPPON DATA 80 Research Group. Combined cardiovascular risk factors and outcome: NIPPON DATA80, 1980-1994. Circ J 2006;70:960-4. [CrossRef]

16. Stürmer T, Sun Y, Sauerland S, Zeissig I, Günther KP, Puhl W, et al. Serum cholesterol and osteoarthritis. The baseline examination of the Ulm Osteoarthritis Study. J Rheumatol 1998;25:1827-32.

17. Kauppila LI, Penttilä A, Karhunen PJ, Lalu K, Hannikainen P. Lumbar disc degeneration and atherosclerosis of the abdominal aorta. Spine (Phila Pa 1976) 1994;19:923-9. [CrossRef]

18. European Association for Cardiovascular Prevention \& Rehabilitation, Reiner Z, Catapano AL, De Backer G, Graham I, Taskinen MR, Wiklund O, et al; ESC Committee for Practice Guidelines (CPG) 2008-2010 and 2010-2012 Committees. ESC/EAS Guidelines for the management of dyslipidaemias: the Task Force for the management of dyslipidaemias of the European Society of Cardiology (ESC) and the European Atherosclerosis Society (EAS). Eur Heart J 2011;32:1769-818. 